\title{
An Algorithm to Determine the Optimum Tilt Angle of a Solar Panel from Global Horizontal Solar Radiation
}

\author{
Emanuele Calabrò \\ Department of Physics, University of Messina, Viale D’Alcontres 31, 98166 Messina, Italy \\ Correspondence should be addressed to Emanuele Calabrò; e.calabro@yahoo.com
}

Received 19 December 2012; Revised 24 February 2013; Accepted 1 March 2013

Academic Editor: Jayanta Deb Mondol

Copyright (C) 2013 Emanuele Calabrò. This is an open access article distributed under the Creative Commons Attribution License, which permits unrestricted use, distribution, and reproduction in any medium, provided the original work is properly cited.

This paper proposes an algorithm to calculate the optimum tilt angle of solar panels by means of global horizontal solar radiation data, provided from Earth-based meteorological stations. This mathematical modeling is based on the maximization of the theoretical expression of the global solar irradiation impinging on an inclined surface, with respect to the slope and orientation of the panel and to the solar hour angle. A set of transcendent equations resulted, whose solutions give the optimum tilt and orientation of a solar panel. A simulation was carried out using global horizontal solar radiation data from the European Solar Radiation Atlas and some empirical models of diffuse solar radiation. The optimum tilt angle resulted was related to latitude by a linear regression with significant correlation coefficients. The standard error of the mean values resulted increased significantly with latitude, suggesting that unreliable values can be provided at high latitudes.

\section{Introduction}

Most countries in the world have realized the need for reduction of gases emission to contrast the adverse global climatic change, encouraging the use of renewable and sustainable sources of energy. Indeed, large quantities of carbon dioxide, nitrogen, and sulfur oxides are emitted in the world by conventional energy sources, which are released to the earth's atmosphere contributing to climate change.

Furthermore, the world will soon run out of its conventional energy resources because of the rapid depletion of fossil fuel reserves. This future scenario and the risks associated with $\mathrm{CO}_{2}$ emissions and global warming have increased the interest in renewable energy.

The major renewable energy systems include photovoltaics (PVs), solar thermal, wind, biomass, hydroelectric, and geothermal. However, among various renewable energy sources, the photovoltaic technology for power generation is considered well-suited technology, particularly for distributed power generation.

Solar panel is the energy conversion fundamental component of PV systems or solar collectors. Solar panels use light energy from the sun to generate electricity through the photovoltaic effect, whereas solar thermal systems generate heat.

The amount of electrical power produced from PV systems is related to the amount of solar irradiation projecting on the modules. Hence, the global solar irradiation on tilted surfaces facing in different directions should be considered to estimate thermal and electrical power obtained in architectural planning.

The literature provides that solar power supplied by the modules depends on many extrinsic factors, such as insolation levels, temperature, load conditions, and orientation of the panel.

The solar radiation is also a function of the nature and extent of cloud cover and of the atmosphere's water vapour content, because solar radiation entering Earth's atmosphere is scattered by atmospheric gases, aerosols, and clouds.

Indeed, meteorological parameters used as predictors include the amount and distribution of clouds or other observations such as the fractional sunshine and water content $[1,2]$.

Aerosols can either absorb or scatter the radiation and alter the energy balance of Earth, especially under clear skies [3]. 
These parameters, obviously, cannot be modified, whereas other variables can be changed to maximize the solar energy acquired by the panel. In fact, the design of a solar energy module involves complex tradeoffs due to the interaction of several factors such as the characteristics of the solar cells, power supply requirements and power management features of the embedded system, application behavior, inclination, and orientation of the panel.

Hence, it is essential to understand and exploit these factors in order to maximize the energy efficiency of a solar module.

In particular, for fixed absorber surfaces, solar energy gain is strictly related to the slope and azimuth angles of a solar panel.

The global solar radiation for inclined surfaces can be calculated by the values of direct and diffuse solar radiation on the corresponding horizontal surface. Meteorological data from all parts of the world are needed to know the horizontal global solar radiation, and, for some regions, measured data may only be applied within a radius of about $50 \mathrm{~km}$ from weather stations. This circumstance leads to interpolate parameters between stations.

Furthermore, spectral irradiance is usually not measured routinely, so that the energy instantaneous production of a solar plant is to rely on appropriate models.

Otherwise, the users need accurate computations of the slope and orientation of solar panels in order to maximize the solar energy that is collected by fixed solar panels.

Advantages of fixed solar panels are mainly related to their tolerance to misalignment, as approximately $20 \%$ of the incident solar radiation is diffuse light, available at any angle of misalignment with the direct sun.

In contrast, the main advantage of tracking systems is to collect solar energy for the longest period of the day with the most accurate alignment as sun's position shifts with the seasons. Indeed, daily solar energy collected was calculated to be $19 \%-24 \%$ higher by a solar PV panel with one axis eastwest tracking system than by a fixed system [4].

Nevertheless, since solar tracking systems have high operation and maintenance costs and are not always applicable, it is often convenient to set the solar collector at a fixed value of an optimum tilt angle [5].

However, some algorithms for the minimization of the energy loss generated by the driving actuator were recently proposed $[6,7]$.

Otherwise, the increase of diffuse solar radiation at low latitudes at some locations with respect to high latitudes makes fixed solar panels a competitive alternative to other energy sources mainly in those locations [8].

Hence, the following main question regarding the design of fixed solar panels arises.

What tilt and orientation of a solar panel have to be chosen to maximize the solar radiation?

Solar radiation impinging on an inclined surface can be divided into direct, diffuse, and ground reflected radiation. Hence, a method to determine these quantities for each latitude has to be studied to answer to that fundamental question.
The diffuse solar component is the most difficult quantity to determine, because the distribution of the sky-diffuse radiance strictly depends on the local condition of the sky.

One way to estimate the diffuse solar component is to study the regression between the global and the diffuse solar radiation at locations where appropriate data are available, establishing models which may be used to predict the diffuse solar radiation.

Liu and Jordan performed the first studies on this subject determining a relationship between daily diffuse and global radiation on a horizontal surface, assuming an isotropic diffusion of solar radiance in the sky [9].

Erbs et al. used a database acquired from four US weather stations, composed of hourly direct normal radiation and global radiation, to develop an estimation of the diffuse fraction of hourly, daily, and monthly average global radiation [10].

Moreover, [11, 12] used also two predictors for their correlations: the clearness index and the solar elevation.

Garrison proposed a model to represent the dependency of the diffuse fraction on the surface albedo, atmospheric precipitable water, atmospheric turbidity, solar elevation, and global horizontal radiation [13].

Reindl et al. considered two more significant predictors, the ambient temperature and relative humidity [14], reducing the standard error of Liu and Jordan-type models.

On the other side, [15] developed an exponential model for the estimation of the direct normal beam radiation from the global radiation, named the Disc model. This model was then improved by [16].

However, accurate mathematical modeling of global and diffuse solar radiation that was used for the simulation in this study is proposed in the following section.

Various optimum tilt angle values were provided in the literature for fixed solar panels.

For instance, Qiu and Riffat suggested the tilt angle of the solar collector set within the optimum tilt angle of $\pm 10^{\circ}$ as an acceptable practice [17].

Other, computations led to the values of $\beta=\varphi \pm 20^{\circ}$ [18], $\beta=\varphi \pm 8^{\circ}$ [19], $\beta=\varphi \pm 5^{\circ}$ [20], and $\beta=\varphi \pm 15^{\circ}$ [21], where $\varphi$ represents the geographical latitude and the signs + and refer to winter and summer months, respectively.

The disagreement among these values may be due to two main reasons:

(1) firstly, the different methods of calculation that were used for the determination of the optimum slope value of a solar panel;

(2) secondly, the different empirical models that were considered for the determination of diffuse solar radiance and its link with the amount of global solar radiation

The aim of this study was to propose an algorithm for the determination of the optimum tilt and orientation of a solar panel using a mathematical model based on the orientation of a generic surface with respect to the position of the sun in the sky. The other physical variables and the empirical model of diffuse solar radiation are considered successively in the algorithm, linking it to a specific location. 


\section{Mathematical Modeling of Global and Diffuse Solar Radiation}

The literature provides several methods to estimate the global and diffuse solar radiation using climatologic parameters.

A typical empirical model is the regression equation of the Angstrom type [22]

$$
\frac{H_{g}}{H_{\mathrm{o}}}=a+b\left(\frac{n}{N}\right),
$$

where $H_{g}$ is the monthly average of daily global solar radiation impinging on a horizontal surface at a location, $H_{o}$ is the monthly mean of daily radiation on a horizontal surface in the absence of atmosphere, $n$ is the monthly mean of daily number hour of observed sunshine, $N$ is the monthly mean value of day length of the interested location, and " $a$ " and " $b$ " are the regression constants, determined from climatological data. The ratio $n / N$ is often called the "possible sunshine hour percentage."

Regression coefficients " $a$ " and " $b$ " can be obtained from some relationships as proposed by $[23,24]$.

A statistically worldwide $5.3 \%$ average decrease of global solar radiation, with largest decline between $45^{\circ}$ and $30^{\circ} \mathrm{N}$, was found by analyzing the data collected in 45 actinometric stations during the years 1958, 1965, 1975, and 1985 [25]. A significant decrease in mean yearly global solar radiation between the years 1964 and 1990 under completely overcast skies was found in some locations in Germany [26].

The observed changes in clear-sky radiation could be related to the recovery by the volcanic eruptions effects, submicron aerosol particles with simultaneous reduction of aerosol mass concentration, and increasing absorption by urban aerosol.

Hence, global horizontal solar irradiation data should be updated and have to be preferred with respect to empirical expression such as (1).

Otherwise, daily extraterrestrial radiation on a horizontal surface, named $H_{o}$, can be computed for the day $n$ from the following equation [27]:

$$
\begin{aligned}
H_{o}= & 86400 * \frac{G_{s c}}{\pi} \\
& \times\left(1+0.033 \cos \left(2 \pi \frac{n}{365}\right)\right) \cos \varphi \cos \delta \\
& *\left( \pm \sqrt{\left(1-\tan ^{2} \varphi \tan ^{2} \delta\right)}\right) \\
+ & \cos ^{-1}(-\tan \varphi \tan \delta) * \sin \varphi \sin \delta,
\end{aligned}
$$

where $G_{\mathrm{sc}}$ is the solar constant $\left(1367 \mathrm{~W} / \mathrm{m}^{2}\right), n$ is the number of the day, $\delta$ is the solar declination, and $\varphi$ is the geographical latitude. The hour angle of sunrise $\omega_{s}$ has been expressed as a function of $\varphi$ and $\delta$ by Cooper's equation.

The ratio of solar radiation at the surface of the Earth to extraterrestrial radiation is called the clearness index, with the monthly average clearness index, $K_{T}$, defined as

$$
K_{T}=\frac{\underline{H}_{g}}{H_{o}},
$$

where $\underline{H}_{g}$ is the monthly average of daily solar radiation on a horizontal surface.

The global horizontal solar irradiation $H_{g}$, provided from meteorological stations, includes the horizontal direct beam irradiation $H_{b}$ and the horizontal diffuse sky irradiation $H_{d}$.

Some models can convert global horizontal irradiation to direct beam irradiation and diffuse sky irradiation on the horizontal plane by means of empirical relationships.

Heliosat is an algorithm which was developed to estimate ground level global horizontal irradiance by using Meteosat satellites images taken in the visible band.

Some predictive models for estimating global solar irradiation have to be used to obtain the solar radiation on a tilted surface, so that the relationship between the global solar irradiation on horizontal planes and that on tilted planes can be evaluated $[9,28-31]$.

Unfortunately, no theoretic relationship between the horizontal sky diffuse irradiation $H_{d}$ and the horizontal global solar irradiation $H_{g}$ can be determined rigorously. Indeed, a double integral like equation (5) of [32] should be solved, which cannot be computed even in the simplest case of uniform and isotropic sky diffuse solar radiation, because the distribution of solar irradiance through the sky is difficult to be represented adequately.

The direct and diffuse components of solar radiation can be estimated using empirical relationships $H_{d}=f\left(H_{g}\right)$ by means of the clearness index $K_{T}$.

Some of these algorithms, requiring the direct normal and diffuse radiation on a horizontal surface as input, can provide very different estimated results in different locations [33].

Indeed, the most considerable cause of error in the computation of the optimum tilt and orientation of a solar panel depends on the model of diffuse solar radiation which is used.

Muneer [34] recommends the model proposed by [35] for the desert and tropical locations:

$$
\frac{H_{d}}{H_{g}}=1.35-1.61 K_{T} .
$$

For temperate climates and locations out with the tropics, equation (5) given by [36] may be used:

$$
\frac{H_{d}}{H_{g}}=1.00-1.13 K_{T} .
$$

The daily horizontal diffuse irradiation $H_{d}$ and direct beam irradiation $H_{b}=H_{g}-H_{d}$ can be obtained by (4) and (5), as well.

\section{The Algorithm to Maximize the Global Solar Radiation on a Fixed Sloped Surface}

3.1. The Case of Isotropic Diffusion. Global solar radiation on a tilted surface $I_{T}$ consists of daily direct solar radiation $I_{b}$, diffuse solar radiation $I_{d}$, and ground reflected radiation $I_{r}$.

Daily solar radiation on a tilted surface for a given month can be estimated as follows [9]:

$$
I_{T}=I_{b}+I_{d}+I_{r} .
$$


The daily direct radiation on a tilted surface $I_{b}$ can be obtained by means of $R_{b}$, the ratio of the average daily direct radiation on a tilted plane to that on a horizontal plane and the parameters to it correlated [37]:

$$
\begin{aligned}
I_{b}= & \frac{\cos \theta}{\cos \theta_{z}}=H_{b} R_{b}, \\
R_{b}= & \cos \beta \\
& -\sin \beta(\sin \delta \cos \varphi \cos \gamma \\
& \quad-\cos \delta \sin \varphi \cos \omega \cos \gamma-\cos \delta \sin \gamma \sin \omega) \\
& \quad \times(\sin \delta \sin \varphi+\cos \delta \cos \varphi \cos \omega)^{-1},
\end{aligned}
$$

where $\beta$ is the slope of the panel as to the horizontal plane, $\gamma$ is the azimuth, $\omega$ is the solar hour angle, $\varphi$ is the latitude, and $\theta$ and $\theta_{z}$ are the solar incidence angle on the considered plane and the solar zenith angle, respectively.

If we consider a uniform and isotropic distribution of diffuse solar radiation over the sky hemisphere, $I_{d}$ would be easily obtained from the simple approximation of [9]:

$$
I_{d}(\text { iso })=\frac{H_{d}(1+\cos \beta)}{2} \text {. }
$$

The evaluation of the ground-reflected diffuse radiation depends on $I_{r}$. Most studies consider that the ground reflection process is ideally isotropic, in which a specific case $I_{r}$ can be simplified as follows:

$$
I_{r}=\frac{H_{g} \rho(1-\cos \beta)}{2}
$$

where $\rho$ represents the diffuse reflectance of the ground (also called ground albedo).

Finally, the daily global solar irradiation on slopes $I_{T}$ can be expressed as the sum of (7), (9), and (10).

The global solar radiation incident on a sloped surface depends on the position of the sun along its daily trajectory (represented by the solar angle $\omega$ ) and on the orientation of the panel (represented by the slope $\beta$ and the azimuth $\gamma$ ).

The other quantities appearing in (6), (7), (8), (9), and (10) depend on the local conditions and can be considered fixed parameters.

The algorithm proposed here is based on the assumption that the daily solar irradiation impinging on a collecting surface is maximum with respect to the angles $\beta, \gamma$, and $\omega$, where $\beta$ is the slope of the panel as to the horizontal plane, $\gamma$ is the azimuth, and $\omega$ is the solar hour angle, respectively.
This physical condition for the maximization of the solar radiation acquired by a solar panel can be represented by the mathematical expressions [8]:

$$
\begin{aligned}
& \frac{\partial I_{T}}{\partial \beta}=0, \\
& \frac{\partial I_{T}}{\partial \gamma}=0, \\
& \frac{\partial I_{T}}{\partial \omega}=0 .
\end{aligned}
$$

Their application to the isotropic model of [9] provides the following expressions [8]:

$$
\begin{aligned}
\frac{\partial I_{T}}{\partial \beta}= & \sin \beta\left(H_{o}+\frac{H_{d}}{2}-\frac{H_{g} \rho}{2}\right) \\
& -\cos \beta H_{o} \\
& \times(\cos \delta \sin \varphi \cos \omega \cos \gamma-\sin \delta \cos \varphi \cos \gamma \\
& +\cos \delta \sin \gamma \sin \omega) \\
& \times(\sin \delta \sin \varphi+\cos \delta \cos \varphi \cos \omega)^{-1}=0, \\
\frac{\partial I_{T}}{\partial \gamma}= & \sin \gamma(\cos \delta \sin \varphi \cos \omega-\sin \delta \cos \varphi) \\
& -\cos \gamma \cos \delta \sin \omega=0, \\
\frac{\partial I_{T}}{\partial \omega}= & \sin \omega \sin \delta \cos \gamma-\cos \delta \cos \varphi \sin \gamma \\
& -\cos \omega \sin \delta \sin \varphi \sin \gamma=0 .
\end{aligned}
$$

This set of equations can be solved with respect to the angles $\beta, \gamma$, and $\omega[8]$ :

$$
\begin{aligned}
& \beta=\tan ^{-1}\left\{H_{o}\right. \\
& \times(\cos \delta \sin \varphi \cos \omega \cos \gamma-\sin \delta \cos \varphi \cos \gamma \\
& +\cos \delta \sin \gamma \sin \omega) \\
& \times\left[\left(H_{o}+\frac{H_{d}}{2}-\frac{H_{g} \rho}{2}\right)\right. \\
& \left.\times(\sin \delta \sin \varphi+\cos \delta \cos \varphi \cos \omega)]^{-1}\right\},
\end{aligned}
$$




$$
\begin{aligned}
& \gamma=\tan ^{-1}\left\{\frac{\cos \delta \sin \omega}{(\cos \delta \sin \varphi \cos \omega-\sin \delta \cos \varphi)}\right\}, \\
& \omega=\sin ^{-1}\{(\sin \delta \cos \delta \sin \gamma \cos \gamma \cos \varphi \\
& \pm {\left[\sin ^{4} \delta\left(\sin ^{2} \varphi \sin ^{2} \gamma \cos ^{2} \gamma+\sin ^{4} \varphi \sin ^{4} \gamma\right)\right.} \\
&\left.\left.-\sin ^{2} \delta \cos ^{2} \delta \sin ^{2} \varphi \cos ^{2} \varphi \sin ^{4} \gamma\right]^{1 / 2}\right) \\
&\left.\times\left(\sin ^{2} \delta \cos ^{2} \gamma+\sin ^{2} \delta \sin ^{2} \varphi \sin ^{2} \gamma\right)^{-1}\right\} .
\end{aligned}
$$

The transcendent equations (13), (14), and (15) can be solved by iterative methods with respect to the angles $\beta, \gamma$, and $\omega$, which provide, respectively, the optimum tilt and orientation of the solar panel and the angular position of the sun in the sky where the maximization of the solar radiation on the panel occurs.

3.2. The Case of Anisotropic Diffusion. The diffuse solar radiance influences the performance of most of the solar energy technologies. In fact, the scattering atmospheric processes redistribute solar energy out of the direct beam into the diffuse radiation. The PV systems, like flat-plate collectors, have the peculiarity to use both direct and diffuse forms of radiation, whereas solar concentrator systems can use only direct radiation.

Unfortunately, the planetary network of diffuse solar radiation measurements stations is poor, whereas global solar radiation data are available for many locations.

Nevertheless, empirical correlations between diffuse and global ratios and diffuse and direct solar radiation can be used to reduce errors in computing hemispherical radiation from estimates of direct and diffuse radiation, especially regarding nonclear sky conditions.

Besides the isotropic model of diffuse solar radiation described in [9], several models have been proposed to represent the anisotropy of the diffuse component $I_{d}$ by means of empirical relations which should modify the expressions (12) and the relative solutions (13), (14), and (15).

The assumption that the diffuse radiation originates entirely from the solar disk gives the relation

$$
I_{d}(\text { disk })=\frac{H_{d} \cos \theta}{\cos \theta_{z}}
$$

which is the modeling opposite to the isotropic one of [9].

Le Quere [38] and Hay and Davies [39] proposed a model for the diffuse solar component as a combination of the two components, that is, (9) and (16),

$$
I_{d}=F * I_{d}(\text { iso })+(1-F) * I_{d}(\text { disk }),
$$

where $(1-F)$ expresses the anisotropy degree.

The value $F=0.8$ was suggested by [38], while [39] assumed the ratio of terrestrial direct radiation to extraterrestrial radiation as the degree of anisotropy $(1-F)$.
Klucher [40] proposed a model in which the isotropic component $I_{d}$ (iso) is multiplied by two factors that represent both circumsolar and horizon brightening:

$$
I_{d}=I_{d} \text { (iso) }\left(1+K \sin ^{3}\left(\frac{\beta}{2}\right)\right)\left(1+K \cos ^{2} \theta \sin ^{3} \theta_{z}\right) \text {, }
$$

where the parameter $K$ expresses the degree of anisotropy as a modulating function of the amount of direct radiation received by the surface, $K=1-H_{d} / H_{g}$ (this model reduces to the Liu-Jordan isotropic model if the ratio of diffuse to global radiation $H_{d} / H_{g}$ is close to the unity).

Further models have been proposed in the literature to perform the anisotropy of diffuse solar irradiance, by means of some coefficients derived from statistical analyses of empirical data for specific locations [41-43].

Nevertheless, the anisotropic models of [38-40] have been taken into account here, because of their easy applicability to every location. In addition, they are extensively validated models that convert hemispherical data on a horizontal surface to hemispherical data on a tilted surface, computing diffuse solar radiation.

The mathematical conditions (11) applied to the models of $[38,39]$ provided the following solutions:

$$
\begin{aligned}
& \beta=\tan ^{-1}\left\{\left[\left(H_{o}+(1-F) H_{d}\right)\right.\right. \\
& \times(\cos \delta \sin \varphi \cos \omega \cos \gamma \\
& -\sin \delta \cos \varphi \cos \gamma+\cos \delta \sin \gamma \sin \omega) \\
& \times\left[\left(H_{o}+\frac{F H_{d}}{2}+(1-F) H_{d}-\frac{H_{g} \rho}{2}\right)\right. \\
& \left.\times(\sin \delta \sin \varphi+\cos \delta \cos \varphi \cos \omega)]^{-1}\right\}, \\
& \gamma=\tan ^{-1}\left\{\left[\left(H_{o}+(1-F) H_{d}\right) \cos \delta \sin \omega\right]\right. \\
& \times\left[\left(H_{o}+(1-F) H_{d}\right)\right. \\
& \left.\times(\cos \delta \sin \varphi \cos \omega-\sin \delta \cos \varphi)]^{-1}\right\}, \\
& \omega=\sin ^{-1}\left\{\left[\left(H_{o}+(1-F) H_{d}\right) \sin \delta \cos \delta \sin \gamma \cos \gamma \cos \varphi\right.\right. \\
& \pm\left[\left[\left(H_{o}+(1-F) H_{d}\right) \sin \delta\right]^{4}\right. \\
& *\left(\sin ^{2} \varphi \sin ^{2} \gamma \cos ^{2} \gamma+\sin ^{4} \varphi \sin ^{4} \gamma\right) \\
& -\left[\left(H_{o}+(1-F) H_{d}\right) \sin \delta \cos \delta\right]^{2} \\
& \left.\left.\times \sin ^{2} \varphi \cos ^{2} \varphi \sin ^{4} \gamma\right]^{1 / 2}\right] \\
& \times\left[\left[\left(H_{o}+(1-F) H_{d}\right) \sin \delta\right]^{2}\right. \\
& \left.\left.\times\left(\cos ^{2} \gamma+\sin ^{2} \varphi \sin ^{2} \gamma\right)\right]^{-1}\right\} \text {. }
\end{aligned}
$$


TABLE 1: Optimum tilt angle values and monthly mean of the daily global solar radiation values computed by means of the algorithm proposed in Section 2 applied to the monthly averages of the daily global horizontal solar irradiation data acquired from 1985 to 1989 at the site of Tripoli (latitude $+32^{\circ} 57^{\prime} \mathrm{N}$; longitude $+13^{\circ} 12^{\prime} \mathrm{E}$ ).

\begin{tabular}{lcccccccccc}
\hline \multirow{2}{*}{ Solar declin. (deg) } & \multicolumn{3}{c}{ Isotropic model } & \multicolumn{2}{c}{ Le Quere's model } & \multicolumn{2}{c}{ Hay and Davies' model } & \multicolumn{2}{c}{ Klucher's model } & \multicolumn{2}{c}{ SEM values } \\
& $\beta(\mathrm{deg})$ & $E\left(\mathrm{MJ} / \mathrm{m}^{2}\right)$ & $\beta(\mathrm{deg})$ & $E\left(\mathrm{MJ} / \mathrm{m}^{2}\right)$ & $\beta(\mathrm{deg})$ & $E\left(\mathrm{MJ} / \mathrm{m}^{2}\right)$ & $\beta(\mathrm{deg})$ & $E\left(\mathrm{MJ} / \mathrm{m}^{2}\right)$ & $\beta(\mathrm{deg})$ & $E\left(\mathrm{MJ} / \mathrm{m}^{2}\right)$ \\
\hline$d_{1}=-21.269$ & 50.7 & 12.44 & 55.3 & 13.05 & 53.3 & 12.73 & 57.0 & 18.54 & 1.17 & 1.26 \\
$d_{2}=-13.289$ & 43.6 & 17.13 & 47.5 & 17.96 & 46.0 & 17.59 & 48.7 & 21.56 & 0.95 & 0.87 \\
$d_{3}=-2.819$ & 33.7 & 22.54 & 37.0 & 23.61 & 35.8 & 23.18 & 37.4 & 24.06 & 0.72 & 0.28 \\
$d_{4}=9.415$ & 21.9 & 27.08 & 24.3 & 28.24 & 23.5 & 27.79 & 23.8 & 26.01 & 0.45 & 0.42 \\
$d_{5}=18.792$ & 12.9 & 29.26 & 14.3 & 30.16 & 13.8 & 29.83 & 13.6 & 27.56 & 0.25 & 0.50 \\
$d_{6}=23.314$ & 8.6 & 30.92 & 9.5 & 31.53 & 9.2 & 31.34 & 8.9 & 29.31 & 0.17 & 0.44 \\
$d_{7}=21.517$ & 10.6 & 31.92 & 11.4 & 32.55 & 11.2 & 32.39 & 10.9 & 30.00 & 0.15 & 0.50 \\
$d_{8}=13.784$ & 18.4 & 30.71 & 19.8 & 31.58 & 19.4 & 31.35 & 19.4 & 28.77 & 0.25 & 0.55 \\
$d_{9}=2.217$ & 29.5 & 25.74 & 31.9 & 26.77 & 31.2 & 26.43 & 32.0 & 25.90 & 0.50 & 0.22 \\
$d_{10}=-9.599$ & 40.9 & 20.16 & 44.0 & 20.99 & 43.0 & 20.69 & 44.9 & 23.73 & 0.75 & 0.69 \\
$d_{11}=-19.148$ & 48.5 & 13.26 & 53.2 & 13.94 & 51.1 & 13.58 & 54.8 & 18.79 & 1.18 & 1.13 \\
$d_{12}=-23.335$ & 51.8 & 10.64 & 57.2 & 11.21 & 54.5 & 10.87 & 58.9 & 16.54 & 1.35 & 1.23 \\
\hline
\end{tabular}

TABLE 2: Optimum tilt angle values and monthly mean of the daily global solar radiation values computed by means of the algorithm proposed in Section 2 applied to the monthly averages of the daily global horizontal solar irradiation data acquired from 1985 to 1989 at the site of Athens (latitude $+37^{\circ} 58^{\prime} \mathrm{N}$; longitude $+23^{\circ} 43^{\prime} \mathrm{E}$ ).

\begin{tabular}{lcccccccccc}
\hline \multirow{2}{*}{ Solar declin. (deg) } & \multicolumn{2}{c}{ Isotropic model } & \multicolumn{2}{c}{ Le Quere's model } & \multicolumn{2}{c}{ Hay and Davies' model } & \multicolumn{3}{c}{ Klucher's model } & \multicolumn{2}{c}{ SEM values } \\
& $\beta(\mathrm{deg})$ & $E\left(\mathrm{MJ} / \mathrm{m}^{2}\right)$ & $\beta(\mathrm{deg})$ & $E\left(\mathrm{MJ} / \mathrm{m}^{2}\right)$ & $\beta(\mathrm{deg})$ & $E\left(\mathrm{MJ} / \mathrm{m}^{2}\right)$ & $\beta(\mathrm{deg})$ & $E\left(\mathrm{MJ} / \mathrm{m}^{2}\right)$ & $\beta(\mathrm{deg})$ & $E\left(\mathrm{MJ} / \mathrm{m}^{2}\right)$ \\
\hline$d_{1}=-21.269$ & 50.1 & 6.58 & 60.5 & 7.42 & 53.5 & 6.73 & 60.2 & 9.89 & 2.22 & 0.66 \\
$d_{2}=-13.289$ & 42.3 & 9.42 & 52.7 & 10.66 & 45.8 & 9.68 & 52.2 & 12.16 & 2.19 & 0.54 \\
$d_{3}=-2.819$ & 33.0 & 13.16 & 42.4 & 14.94 & 36.2 & 13.59 & 40.9 & 14.65 & 1.87 & 0.37 \\
$d_{4}=9.415$ & 24.7 & 20.47 & 30.2 & 22.59 & 27.1 & 21.24 & 28.8 & 20.13 & 1.03 & 0.47 \\
$d_{5}=18.792$ & 17.1 & 24.75 & 20.5 & 26.65 & 18.7 & 25.56 & 18.9 & 23.23 & 0.61 & 0.62 \\
$d_{6}=23.314$ & 13.6 & 28.03 & 15.8 & 29.58 & 14.8 & 28.82 & 14.6 & 26.03 & 0.39 & 0.66 \\
$d_{7}=21.517$ & 15.7 & 29.27 & 17.7 & 30.82 & 16.9 & 30.15 & 16.8 & 26.97 & 0.36 & 0.73 \\
$d_{8}=13.784$ & 22.9 & 27.03 & 25.9 & 28.83 & 24.7 & 28.03 & 25.3 & 25.33 & 0.55 & 0.65 \\
$d_{9}=2.217$ & 33.6 & 21.73 & 37.8 & 23.49 & 36.0 & 22.62 & 38.2 & 22.39 & 0.90 & 0.31 \\
$d_{10}=-9.599$ & 43.2 & 14.21 & 49.5 & 15.64 & 46.2 & 14.77 & 50.6 & 17.48 & 1.45 & 0.62 \\
$d_{11}=-19.148$ & 48.2 & 7.38 & 58.5 & 8.32 & 51.6 & 7.56 & 58.2 & 10.63 & 2.19 & 0.65 \\
$d_{12}=-23.335$ & 52.3 & 5.92 & 62.5 & 6.67 & 55.6 & 6.06 & 62.2 & 9.35 & 2.18 & 0.69 \\
\hline
\end{tabular}

TABLE 3: Optimum tilt angle values and monthly mean of the daily global solar radiation values computed by means of the algorithm proposed in Section 2 applied to the monthly averages of the daily global horizontal solar irradiation data acquired from 1985 to 1989 at the site of Rome (latitude $+41^{\circ} 54^{\prime} \mathrm{N}$; longitude $+12^{\circ} 27^{\prime} \mathrm{E}$ ).

\begin{tabular}{|c|c|c|c|c|c|c|c|c|c|c|}
\hline \multirow{2}{*}{ Solar declin. (deg) } & \multicolumn{2}{|c|}{ Isotropic model } & \multicolumn{2}{|c|}{ Le Quere's model } & \multicolumn{2}{|c|}{ Hay and Davies' model } & \multicolumn{2}{|c|}{ Klucher's model } & \multicolumn{2}{|c|}{ SEM values } \\
\hline & $\beta(\mathrm{deg})$ & $E\left(\mathrm{MJ} / \mathrm{m}^{2}\right)$ & $\beta$ (deg) & $E\left(\mathrm{MJ} / \mathrm{m}^{2}\right)$ & $\beta$ (deg) & $E\left(\mathrm{MJ} / \mathrm{m}^{2}\right)$ & $\beta$ (deg) & $E\left(\mathrm{MJ} / \mathrm{m}^{2}\right)$ & $\beta$ (deg) & $E\left(\mathrm{MJ} / \mathrm{m}^{2}\right)$ \\
\hline$d_{1}=-21.269$ & 57.5 & 6.93 & 64.6 & 7.93 & 60.4 & 7.21 & 65.8 & 11.47 & 1.66 & 0.91 \\
\hline$d_{2}=-13.289$ & 49.5 & 10.56 & 56.9 & 12.04 & 52.7 & 11.02 & 58.1 & 14.38 & 1.71 & 0.74 \\
\hline$d_{3}=-2.819$ & 40.1 & 16.05 & 46.7 & 18.15 & 43.1 & 16.82 & 47.4 & 18.12 & 1.47 & 0.44 \\
\hline$d_{4}=9.415$ & 28 & 20.02 & 34.3 & 22.67 & 30.7 & 20.95 & 33.3 & 19.77 & 1.22 & 0.56 \\
\hline$d_{5}=18.792$ & 20.2 & 24.07 & 24.6 & 26.66 & 22.2 & 25.07 & 23 & 22.46 & 0.79 & 0.76 \\
\hline$d_{6}=23.314$ & 16.8 & 27.14 & 20 & 29.45 & 18.4 & 28.17 & 18.5 & 24.90 & 0.57 & 0.83 \\
\hline$d_{7}=21.517$ & 19 & 28.82 & 21.9 & 31.08 & 20.7 & 29.98 & 20.9 & 26.21 & 0.52 & 0.90 \\
\hline$d_{8}=13.784$ & 26.5 & 26.82 & 30.1 & 29.19 & 28.6 & 28.07 & 29.7 & 24.99 & 0.70 & 0.78 \\
\hline$d_{9}=2.217$ & 36.5 & 19.81 & 41.8 & 22.06 & 39.2 & 20.80 & 42.3 & 20.75 & 1.15 & 0.40 \\
\hline$d_{10}=-9.599$ & 49 & 15.29 & 53.6 & 16.83 & 51.6 & 16.04 & 55.3 & 19.35 & 1.17 & 0.76 \\
\hline$d_{11}=-19.148$ & 55.7 & 8.01 & 62.6 & 9.13 & 58.6 & 8.35 & 63.9 & 12.56 & 1.63 & 0.90 \\
\hline$d_{12}=-23.335$ & 61.5 & 7.05 & 66.7 & 7.94 & 64 & 7.38 & 68.4 & 12.76 & 1.31 & 1.15 \\
\hline
\end{tabular}


TABLE 4: Optimum tilt angle values and monthly mean of the daily global solar radiation values computed by means of the algorithm proposed in Section 2 applied to the monthly averages of the daily global horizontal solar irradiation data acquired from 1985 to 1989 at the site of Paris (latitude $+48^{\circ} 51^{\prime} \mathrm{N}$; longitude $+2^{\circ} 20^{\prime} \mathrm{E}$ ).

\begin{tabular}{lcccccccccc}
\hline \multirow{2}{*}{ Solar declin. (deg) } & \multicolumn{2}{c}{ Isotropic model } & \multicolumn{2}{c}{ Le Quere's model } & \multicolumn{2}{c}{ Hay and Davies' model } & \multicolumn{2}{c}{ Klucher's model } & \multicolumn{2}{c}{ SEM values } \\
& $\beta(\mathrm{deg})$ & $E\left(\mathrm{MJ} / \mathrm{m}^{2}\right)$ & $\beta(\mathrm{deg})$ & $E\left(\mathrm{MJ} / \mathrm{m}^{2}\right)$ & $\beta(\mathrm{deg})$ & $E\left(\mathrm{MJ} / \mathrm{m}^{2}\right)$ & $\beta(\mathrm{deg})$ & $E\left(\mathrm{MJ} / \mathrm{m}^{2}\right)$ & $\beta(\mathrm{deg})$ & $E\left(\mathrm{MJ} / \mathrm{m}^{2}\right)$ \\
\hline$d_{1}=-21.269$ & 56.7 & 3.98 & 68.1 & 4.94 & 59.9 & 4.10 & 66.5 & 6.54 & 2.33 \\
$d_{2}=-13.289$ & 46.9 & 6.05 & 60.4 & 7.53 & 50.4 & 6.25 & 58 & 8.21 & 2.74 & 0.51 \\
$d_{3}=-2.819$ & 38.3 & 10.30 & 50.2 & 12.66 & 41.7 & 10.73 & 48.3 & 11.94 & 2.41 & 0.47 \\
$d_{4}=9.415$ & 28.7 & 15.74 & 38.1 & 18.95 & 31.7 & 16.47 & 35.7 & 15.92 & 1.80 & 0.64 \\
$d_{5}=18.792$ & 20.4 & 17.66 & 28.4 & 21.00 & 22.8 & 18.36 & 24.5 & 16.94 & 1.45 & 0.76 \\
$d_{6}=23.314$ & 18.3 & 22.16 & 23.9 & 25.46 & 20.4 & 23.11 & 21.2 & 20.59 & 1.00 & 0.88 \\
$d_{7}=21.517$ & 21.1 & 24.83 & 25.9 & 28.13 & 23.3 & 26.05 & 24.2 & 22.76 & 0.87 & 0.97 \\
$d_{8}=13.784$ & 27.8 & 21.73 & 33.9 & 25.06 & 30.5 & 22.92 & 32.9 & 20.72 & 1.17 & 0.80 \\
$d_{9}=2.217$ & 39 & 17.48 & 45.7 & 20.24 & 42 & 18.50 & 46.2 & 18.67 & 1.46 & 0.49 \\
$d_{10}=-9.599$ & 48.7 & 10.22 & 57.1 & 12.14 & 52 & 10.75 & 57.9 & 13.32 & 1.88 & 0.60 \\
$d_{11}=-19.148$ & 58.1 & 5.93 & 66.3 & 7.12 & 61.1 & 6.21 & 66.9 & 9.67 & 1.83 & 0.73 \\
$d_{12}=-23.335$ & 62.6 & 4.31 & 70.3 & 5.22 & 65.3 & 4.50 & 70.6 & 8.02 & 1.70 & 0.74 \\
\hline
\end{tabular}

Equations (19), (20), and (21) can be solved by iterative methods with respect to the angles $\beta, \gamma$, and $\omega$. The mathematical conditions (11) applied to the model of [40], represented by (18), provided the following expressions:

$$
\begin{aligned}
\frac{\partial I_{T}}{\partial \beta}= & -H_{o} \sin \beta \\
- & H_{o} \cos \beta[(\sin \delta \cos \varphi \cos \gamma-\cos \delta \sin \varphi \cos \omega \cos \gamma \\
& -\cos \delta \sin \gamma \sin \omega) \\
& \left.\times(\sin \delta \sin \varphi+\cos \delta \cos \varphi \cos \omega)^{-1}\right] \\
- & H_{d} \sin \beta \frac{\left(1+F \sin ^{3}(\beta / 2)\right)}{2} \\
& +3 \sin ^{2}\left(\frac{\beta}{2}\right) H_{d} F \frac{(1+\cos \beta)}{2}-\frac{H_{d} F \sin \beta q_{1} q_{2} q_{3}}{2} \\
& +3 F \sin ^{2}\left(\frac{\beta}{2}\right) q_{1} q_{2} H_{d} F \frac{(1+\cos \beta)}{2} \\
& +\frac{H_{g} \rho \sin \beta}{2}+H_{d} F(1+\cos \beta)\left(\sqrt{q_{1}}\right) \\
& *[\cos \beta(\cos \delta \sin \varphi \cos \omega \cos \gamma+\cos \delta \sin \gamma \sin \omega \\
& \quad-\sin \delta \cos \varphi \cos \gamma) \\
& -\sin \beta(\sin \delta \sin \varphi+\cos \delta \cos \varphi \cos \omega)] q_{2} q_{3}=0,
\end{aligned}
$$

$$
\begin{aligned}
\frac{\partial I_{T}}{\partial \gamma}= & \sin \beta\left(H_{o} \sin \delta \cos \varphi \sin \gamma-H_{o} \cos \delta \sin \varphi \cos \omega \sin \gamma\right. \\
& \left.+H_{o} \cos \delta \cos \gamma \sin \omega\right) \\
& \times(\sin \delta \sin \varphi+\cos \delta \cos \varphi \cos \omega)^{-1} \\
+ & \left(1+F \sin ^{3}\left(\frac{\beta}{2}\right)\right) H_{d} F(1+\cos \beta) q_{2}\left(\sqrt{q_{1}}\right) \\
& \times[\sin \beta(\sin \delta \cos \varphi \sin \gamma+\cos \delta \cos \gamma \sin \omega \\
& \quad-\cos \delta \sin \varphi \cos \omega \sin \gamma)]=0
\end{aligned}
$$

$$
\begin{aligned}
\frac{\partial I_{T}}{\partial \omega}= & \frac{H_{o} \sin \beta(\cos \delta \cos \omega \sin \gamma-\cos \delta \sin \varphi \sin \omega \cos \gamma)}{\sin \delta \sin \varphi+\cos \delta \cos \varphi \cos \omega} \\
& +\left(1+F \sin ^{3}\left(\frac{\beta}{2}\right)\right) H_{d} F(1+\cos \beta) q_{2} \sqrt{q_{1}} \\
& \times[\sin \beta(\cos \omega \cos \delta \sin \gamma-\sin \omega \cos \delta \sin \varphi \cos \gamma) \\
& \quad-\cos \beta \cos \delta \cos \varphi \sin \omega] \\
& +\left(1+F \sin ^{3}\left(\frac{\beta}{2}\right)\right) H_{d} F(1+\cos \beta)\left(\frac{3}{4}\right) q_{1} \\
& \times\left[1-(\sin \delta \sin \varphi+\cos \delta \cos \varphi \cos \omega)^{2}\right]^{1 / 2} \\
& \times(\sin \omega \cos \delta \cos \varphi)=0,
\end{aligned}
$$

where

$$
\begin{aligned}
q_{1}= & {[\cos \beta(\sin \delta \sin \varphi+\cos \delta \cos \varphi \cos \omega)} \\
& +\sin \beta(\cos \delta \sin \varphi \cos \omega \cos \gamma \\
& +\cos \delta \sin \omega \sin \gamma-\sin \delta \cos \varphi \cos \gamma)]^{2}, \\
q_{2}= & {\left[1-(\sin \delta \sin \varphi+\cos \delta \cos \varphi \cos \omega)^{2}\right]^{3 / 2}, } \\
q_{3}= & {\left[1+F \sin ^{3}\left(\frac{\beta}{2}\right)\right] . }
\end{aligned}
$$

This set of equation can be solved only using iterative methods.

\section{Applying the Maximization Algorithm to a Data Set of Global Horizontal Solar Radiation}

The data collected at the European Solar Radiation Atlas (available at the Internet site HelioClim) were used to test the algorithm proposed here. 
TABLE 5: Optimum tilt angle values and monthly mean of the daily global solar radiation values computed by means of the algorithm proposed in Section 2 applied to the monthly averages of the daily global horizontal solar irradiation data acquired from 1985 to 1989 at the site of London (latitude $+51^{\circ} 32^{\prime} \mathrm{N}$; longitude $0^{\circ} 05^{\prime} \mathrm{W}$ ).

\begin{tabular}{lcccccccccc}
\hline \multirow{2}{*}{ Solar declin. (deg) } & \multicolumn{2}{c}{ Isotropic model } & \multicolumn{2}{c}{ Le Quere's model } & \multicolumn{2}{c}{ Hay and Davies' model } & \multicolumn{2}{c}{ Klucher's model } & \multicolumn{2}{c}{ SEM values } \\
& $\beta(\mathrm{deg})$ & $E\left(\mathrm{MJ} / \mathrm{m}^{2}\right)$ & $\beta(\mathrm{deg})$ & $E\left(\mathrm{MJ} / \mathrm{m}^{2}\right)$ & $\beta(\mathrm{deg})$ & $E\left(\mathrm{MJ} / \mathrm{m}^{2}\right)$ & $\beta(\mathrm{deg})$ & $E\left(\mathrm{MJ} / \mathrm{m}^{2}\right)$ & $\beta(\mathrm{deg})$ & $E\left(\mathrm{MJ} / \mathrm{m}^{2}\right)$ \\
\hline$d_{1}=-21.269$ & 61.8 & 2.24 & 73.8 & 3.10 & 64.7 & 2.32 & 70.6 & 4.00 & 2.36 \\
$d_{2}=-13.289$ & 52.1 & 4.39 & 66.1 & 5.95 & 55.5 & 4.56 & 63 & 6.26 & 2.80 & 0.46 \\
$d_{3}=-2.819$ & 41.4 & 7.79 & 55.9 & 10.46 & 44.9 & 8.14 & 52.6 & 9.26 & 2.90 & 0.52 \\
$d_{4}=9.415$ & 32 & 13.31 & 44 & 17.36 & 35.3 & 14.02 & 40.8 & 13.70 & 2.33 & 0.80 \\
$d_{5}=18.792$ & 25.8 & 18.88 & 34.6 & 23.65 & 28.6 & 19.96 & 31.7 & 17.86 & 1.45 & 1.09 \\
$d_{6}=23.314$ & 20.7 & 17.87 & 29.9 & 22.55 & 23.1 & 18.71 & 25.2 & 16.84 & 1.69 & 1.07 \\
$d_{7}=21.517$ & 21.7 & 16.61 & 31.7 & 21.20 & 24.2 & 17.37 & 26.7 & 15.83 & 1.84 & 1.03 \\
$d_{8}=13.784$ & 28.2 & 14.54 & 39.6 & 18.85 & 31.2 & 15.29 & 35.8 & 14.44 & 2.17 & 0.90 \\
$d_{9}=2.217$ & 39.1 & 11.02 & 51.1 & 14.37 & 42.6 & 11.63 & 49.3 & 12.24 & 2.43 & 1.13 \\
$d_{10}=-9.599$ & 54.9 & 8.65 & 62.9 & 10.84 & 58 & 9.23 & 63.8 & 11.86 & 1.82 \\
$d_{11}=-19.148$ & 63.1 & 3.68 & 72.0 & 4.84 & 65.9 & 3.87 & 71.3 & 6.53 & 1.13 \\
$d_{12}=-23.335$ & 64.2 & 1.73 & 75.8 & 2.41 & 66.8 & 1.78 & 72.2 & 3.31 & 2.26 \\
\hline
\end{tabular}

TABLE 6: Optimum tilt angle values and monthly mean of the daily global solar radiation values computed by means of the algorithm proposed in Section 2 applied to the monthly averages of the daily global horizontal solar irradiation data acquired from 1985 to 1989 at the site of Stockholm (latitude $+59^{\circ} 17^{\prime} \mathrm{N}$; longitude $+18^{\circ} 03^{\prime} \mathrm{E}$ ). The monthly mean of the daily global solar radiation was not acquired in the periods relative to the solar declinations $d_{1}, d_{11}$, and $d_{12}$.

\begin{tabular}{|c|c|c|c|c|c|c|c|c|c|c|}
\hline \multirow{2}{*}{ Solar declin. (deg) } & \multicolumn{2}{|c|}{ Isotropic model } & \multicolumn{2}{|c|}{ Le Quere's model } & \multicolumn{2}{|c|}{ Hay and Davies' model } & \multicolumn{2}{|c|}{ Klucher's model } & \multicolumn{2}{|c|}{ SEM values } \\
\hline & $\beta(\mathrm{deg})$ & $E\left(\mathrm{MJ} / \mathrm{m}^{2}\right)$ & $\beta(\mathrm{deg})$ & $E\left(\mathrm{MJ} / \mathrm{m}^{2}\right)$ & $\beta(\mathrm{deg})$ & $E\left(\mathrm{MJ} / \mathrm{m}^{2}\right)$ & $\beta(\mathrm{deg})$ & $E\left(\mathrm{MJ} / \mathrm{m}^{2}\right)$ & $\beta(\operatorname{deg})$ & $E\left(\mathrm{MJ} / \mathrm{m}^{2}\right)$ \\
\hline$d_{1}=-21.269$ & & n.c. & & n.c. & & n.c. & & n.c. & n.c. & n.c. \\
\hline$d_{2}=-13.289$ & 67.1 & 5.18 & 73.2 & 6.99 & 69.5 & 5.65 & 73.8 & 8.79 & 1.37 & 0.70 \\
\hline$d_{3}=-2.819$ & 54.7 & 10.25 & 63.1 & 13.77 & 57.9 & 11.15 & 63.8 & 12.56 & 1.88 & 0.68 \\
\hline$d_{4}=9.415$ & 43.1 & 18.64 & 51.3 & 24.32 & 46.4 & 20.37 & 51.8 & 18.32 & 1.80 & 1.19 \\
\hline$d_{5}=18.792$ & 33.0 & 21.99 & 41.8 & 29.10 & 36.2 & 23.88 & 40.7 & 19.95 & 1.77 & 1.70 \\
\hline$d_{6}=23.314$ & 29.5 & 25.39 & 37.3 & 32.92 & 32.4 & 27.54 & 35.9 & 22.19 & 1.52 & 1.95 \\
\hline$d_{7}=21.517$ & 29.8 & 21.84 & 39.0 & 29.12 & 32.9 & 23.59 & 37.0 & 19.68 & 1.78 & 1.75 \\
\hline$d_{8}=13.784$ & 33.8 & 14.17 & 46.5 & 20.12 & 37.2 & 15.15 & 43.4 & 13.98 & 2.50 & 1.25 \\
\hline$d_{9}=2.217$ & 46.3 & 10.25 & 58.0 & 14.45 & 49.8 & 11.02 & 56.9 & 11.52 & 2.44 & 0.79 \\
\hline$d_{10}=-9.599$ & 60.5 & 5.65 & 69.5 & 7.93 & 63.5 & 6.09 & 69.3 & 8.25 & 1.92 & 0.56 \\
\hline$d_{11}=-19.148$ & & n.c. & & n.c. & & n.c. & & n.c. & n.c. & n.c. \\
\hline$d_{12}=-23.335$ & & n.c. & & n.c. & & n.c. & & n.c. & n.c. & n.c. \\
\hline
\end{tabular}

In particular, the global horizontal solar radiation $H_{g}$ relative to Tripoli, Athens, Rome, Paris, London, and Stockholm, located from $32^{\circ}$ to $59^{\circ}$ north latitude, was considered by averaging the values on a monthly basis from 1985 to 1989 and was used for this simulation.

The calculations of $\beta, \gamma$, and $\omega$ were carried out at every month because their time variation cannot be neglected [44].

The solar declination values $\delta$ were computed at the middle of every month by Cooper's equation, which was also used to calculate the sunset hour angle $\omega_{s}$ [37]. Daily extraterrestrial radiation on a horizontal surface, $H_{o}$, was computed at the same day by [27]; equation (5) from [39] was used as a relationship between $H_{d}$ and $H_{g}$. Ground albedo was fixed at the typical value $\rho=0.20$.
The isotropic model of [9] and the anisotropic models of [38-40] were used to calculate the diffuse solar component $H_{d}$.

The solutions of (14), (15), (20), (21), (23), and (24) gave the values $\gamma=0^{\circ}$ and $\omega=0^{\circ}$, confirming that the optimum orientation of a solar panel is toward South, where in fact the solar hour angle at solar noon must be zero, as it is defined.

Nevertheless, other models of the solar diffuse component could provide different values.

The optimum tilt angle values, provided by the solutions of (13), (19), (22), were reported on Tables 1, 2, 3, 4, 5, and 6.

The corresponding monthly average of the daily global solar radiation (measured in $\mathrm{MJ} / \mathrm{m}^{2}$ ) collected by a surface inclined at each $\beta$ value was indicated in Tables $1-6$, as 
TABLE 7: The average $\beta$ of the optimum tilt angle values computed using the diffuse solar radiation models, relative to the latitude values used above. A linear regression with 95\% confidence interval provided the coefficients $a_{1}$ and $a_{2}$ and the correlation coefficients ranging from 0.944 to 0.993 , reported in the last column.

\begin{tabular}{|c|c|c|c|c|c|c|c|c|}
\hline \multirow{2}{*}{$\underline{\beta}\left(l_{1}\right)$} & \multirow{2}{*}{$\underline{\beta}\left(l_{2}\right)$} & \multirow[b]{2}{*}{$\underline{\beta}\left(l_{3}\right)$} & \multirow[b]{2}{*}{$\underline{\beta}\left(l_{4}\right)$} & \multirow[b]{2}{*}{$\underline{\beta}\left(l_{5}\right)$} & \multirow[b]{2}{*}{$\underline{\beta}\left(l_{6}\right)$} & \multicolumn{2}{|c|}{ Coefficients } & \multirow[b]{2}{*}{ Correlation $r$} \\
\hline & & & & & & $a_{1}$ & $a_{2}$ & \\
\hline 54.07 & 56.08 & 62.07 & 62.80 & 67.72 & - & 31.33 & 0.68 & 0.953 \\
\hline 46.45 & 48.25 & 54.30 & 53.93 & 59.17 & 70.90 & 16.25 & 0.86 & 0.944 \\
\hline 35.97 & 38.13 & 44.32 & 44.62 & 48.70 & 59.87 & 6.80 & 0.84 & 0.957 \\
\hline 23.37 & 27.70 & 31.57 & 33.55 & 38.03 & 48.15 & -6.07 & 0.87 & 0.975 \\
\hline 13.65 & 18.80 & 22.50 & 24.03 & 30.17 & 37.92 & -14.95 & 0.87 & 0.978 \\
\hline 9.05 & 14.70 & 18.42 & 20.95 & 24.73 & 33.77 & -19.27 & 0.87 & 0.985 \\
\hline 11.03 & 16.78 & 20.62 & 23.62 & 26.08 & 34.67 & -15.65 & 0.83 & 0.988 \\
\hline 19.25 & 24.70 & 28.72 & 31.27 & 33.70 & 40.22 & -4.23 & 0.75 & 0.989 \\
\hline 31.15 & 36.40 & 39.95 & 43.22 & 45.53 & 52.75 & 6.42 & 0.77 & 0.993 \\
\hline 43.20 & 47.37 & 52.37 & 53.93 & 59.90 & 65.70 & 15.84 & 0.83 & 0.983 \\
\hline 51.90 & 54.13 & 60.20 & 63.10 & 68.07 & - & 23.61 & 0.84 & 0.977 \\
\hline 55.60 & 58.15 & 65.15 & 67.20 & 69.75 & - & 30.56 & 0.76 & 0.968 \\
\hline
\end{tabular}

TABLE 8: The average standard error of the mean (SEM) of the tilt angles and of the monthly average of the daily global solar radiation values of diffuse solar radiation, computed separately for summer months (solar declinations $d_{4}-d_{9}$ ) and for winter months (solar declinations $d_{1}-d_{3}$ and $d_{10}-d_{12}$ ) as a function of latitude (the correlation coefficient $r$ relative to winter months was computed excluding the values relative to the latitude of Stockholm).

Average values of SEM values

Latitude (deg) Summer months Winter months

\begin{tabular}{lcccc} 
& $\beta$ & $E$ & $\beta$ & $E$ \\
\hline 32.95 & 0.30 & 0.44 & 1.01 & 0.91 \\
37.96 & 0.64 & 0.57 & 2.01 & 0.59 \\
41.90 & 0.82 & 0.71 & 1.50 & 0.82 \\
48.85 & 1.26 & 0.75 & 2.15 & 0.58 \\
51.53 & 2.02 & 0.92 & 2.33 & 0.46 \\
59.28 & 1.96 & 1.44 & n.c. & n.c. \\
Correlation & 0.956 & 0.935 & 0.835 & -0.789 \\
coefficient $r$ & & & & \\
\hline
\end{tabular}

well. Such a value can be considered representative of the conversion efficiency of a PV module, because of a linear relationship with solar radiation rate [45].

The results led to the following considerations.

(1) The optimum tilt angle values of solar panels determined for winter months were confirmed to be very different from the values recommended for summer months.

(2) The value $\gamma=0^{\circ}$ was confirmed to be the optimum orientation value for a solar panel.

(3) The disagreement among the models of diffuse solar irradiance resulted was relevant for the winter months (represented by the solar declinations $d_{1-3}$ and $d_{10-12}$, corresponding to the first three and the last three rows of Tables 1-6) and resulted in increase with increasing latitude.

Furthermore, the optimum tilt angle values were averaged for each monthly solar declination and were reported as a function of latitude in Table 7 . The average tilt angles resulted were significantly related to latitudes. A correlation between these two sets of variables was studied, applying a linear relationship to predict the value of the optimum tilt angle for a given geographical latitude.

In particular, the regression line was performed by the method of least squares, to make the sum of the squares of the differences between the ordinates of the points and those on the straight line as small as possible. The correlation coefficient " $r$ " of the variables was calculated, defined as their covariance (that measures how the two variables are linearly related) divided by the product of their individual standard deviations. In addition, a confidence interval was considered to know how accurate is the regression.

Linear regressions with $95 \%$ confidence interval provided correlation coefficients ranging from 0.944 to 0.993 , reported in the last column of Table 7 (larger correlation values were found for summer months). Two typical fits for two solar declinations are shown in Figures 1(a) and 1(b).

This result shows that the optimum tilt angle of a solar panel could be easily obtained as a function of geographical latitude by means of the coefficients $a_{1}$ and $a_{2}$ of a linear regression $\beta=a_{1}+a_{2} * \varphi$. The coefficients $a_{1}$ and $a_{2}$, obtained by the regression, depend on the solar declination that was used.

Furthermore, the application of the algorithm showed that the differences among the tilt angle values, computed using various models of diffuse solar irradiance, increase with increasing of the geographical latitude, suggesting that further empirical correlations between diffuse and global ratios and diffuse and direct solar radiation should be investigated, especially at high latitudes. 


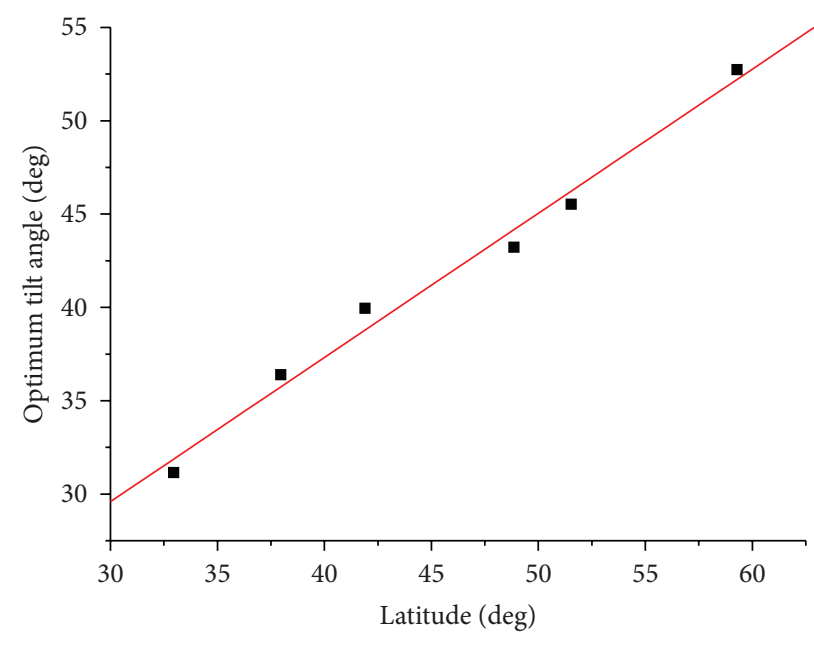

(a)

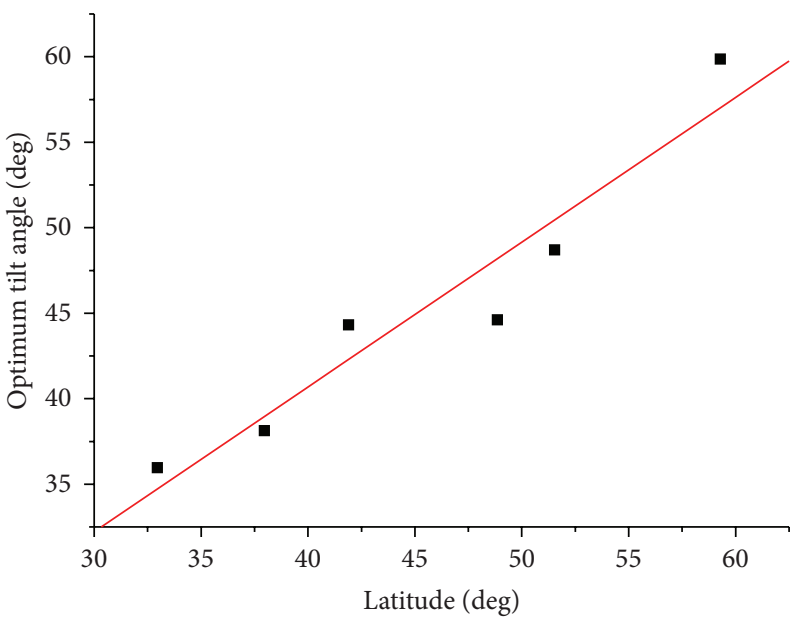

(b)

Figure 1: Average values of optimum tilt angles, computed using diffuse solar radiation models, as a function of latitude, relative to the solar declination $d_{9}$ (a) and to the solar declination $d_{3}$ (b). Linear regressions with $95 \%$ confidence interval provided the correlation coefficients $r=0.993$ and $r=0.957$, respectively.

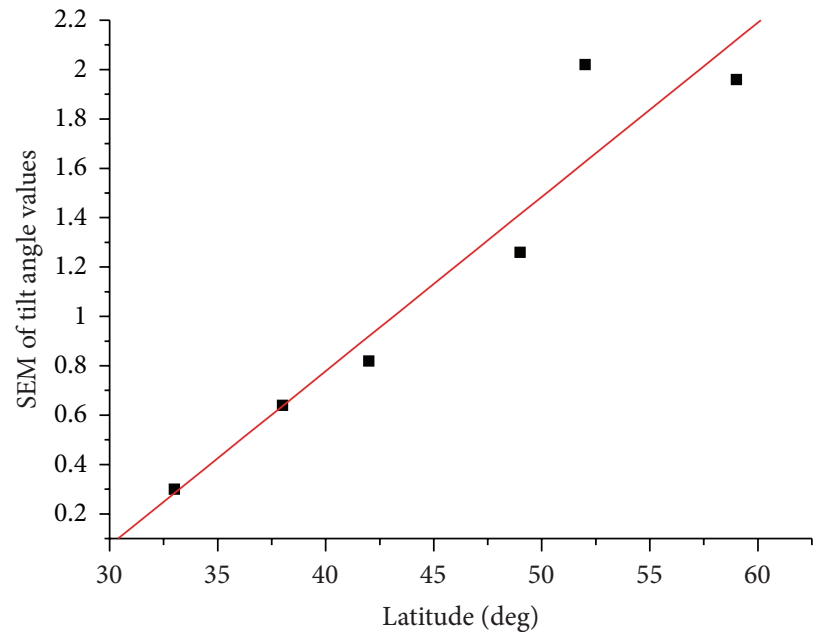

(a)

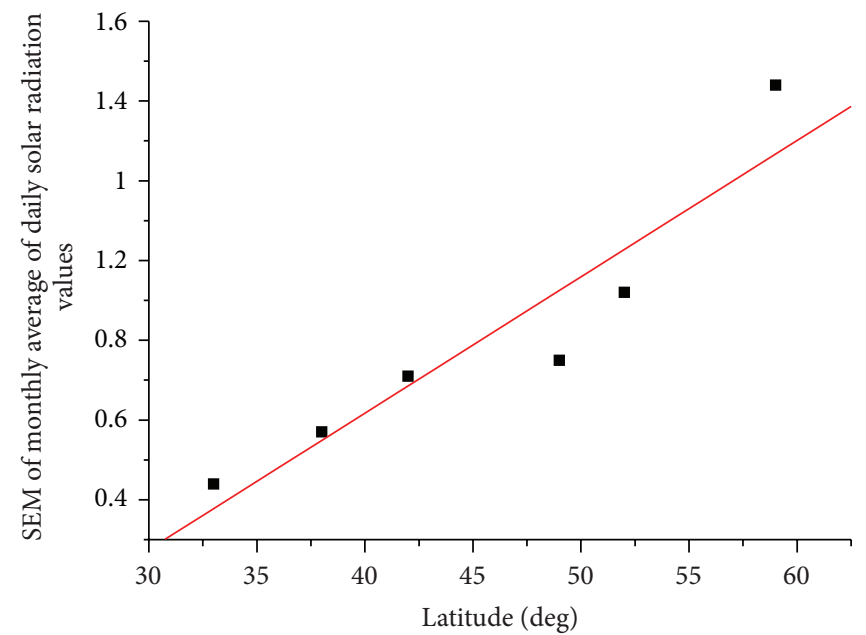

(b)

FIGURE 2: The standard error of the mean (SEM) of the tilt angle values (a) and of the monthly average of the daily global solar radiation values (b), computed for the summer months (solar declinations $d_{4}-d_{9}$ ) as a function of latitude. The linear fits provided the correlation coefficients $r=0.956$ and $r=0.935$, respectively.

Finally, the standard error of the mean (SEM) of the tilt angles and of the monthly average of the daily global solar radiation values was computed and reported in the last column of Tables 1-6, to quantify the disagreement among the various models of diffuse solar irradiance used here.

The average values of these SEM values were computed separately for summer months and for winter months and reported in Table 8.

A significant correlation between the averages of these SEM values and the latitudes was found for summer months. In fact, a linear regression with $95 \%$ confidence interval provided the correlation coefficients $r=0.956$ and $r=0.935$ for the tilt angles and the monthly average of the daily global solar radiation values, respectively. These linear regressions were represented in Figures 2(a) and 2(b).

Regarding the winter months, lower correlations were found (see Table 8). Nevertheless, the values obtained for the winter months can be considered less reliable because the decrease in intensity of direct and diffuse solar radiation during winter months produces an increase in the relative error for estimating the tilt angles and the monthly average of the daily global solar radiation values. 


\section{Conclusions}

The method of maximization of global solar radiation proposed here led to take into account a set of equations, which can be solved with respect to the slope $\beta$ and the azimuth $\gamma$ of a collecting surface and to the solar hour angle $\omega$. The proposed algorithm was applied to some models of diffuse solar irradiance, using global horizontal solar radiation data from the European Solar Radiation Atlas. The relative equations provided a set of angles $\beta, \gamma$, and $\omega$, as a function of the other physical parameters. The better solar panel orientation toward South and the large time dependence of the optimum tilt angle were confirmed, suggesting the use of semifixed panels on building structures.

The solutions of the set of equations provided tilt angles and monthly average of daily global solar radiation values strictly related to the model of diffuse solar irradiation which was used.

The computed tilt angles resulted were significantly related to the latitude value, because linear regressions with 95\% confidence interval provided correlation coefficients ranging from 0.944 to 0.993 . This result allows to estimate the optimum tilt angle of a solar panel as a function of latitude by means of a linear regression, whose coefficients depend on global horizontal solar radiation data.

Nevertheless, relevant differences among the monthly average of the daily global solar radiation and the tilt angle values, obtained using different models of diffuse solar radiation, were highlighted by the simulations performed separately for summer and winter months.

The standard error of the mean of such values resulted in significant increase with increasing latitude for summer months, leading to the conclusion that values unreliable for the optimum tilt angle of a solar panel can be provided by the models of diffuse solar radiation at high latitudes.

Hence, further research is needed to better estimate the diffuse solar radiation.

\section{References}

[1] ASHRAE Handbook: HVAC Applications, ASHRAE, Atlanta, Ga, USA, 1999.

[2] M. Iqbal, "Estimation of the monthly average of the diffuse component of total insolation on a horizontal surface," Solar Energy, vol. 20, no. 1, pp. 101-105, 1978.

[3] C. A. Gueymard, "Importance of atmospheric turbidity and associated uncertainties in solar radiation and luminous efficacy modelling," Energy, vol. 30, no. 9, pp. 1603-1621, 2005.

[4] O. C. Vilela, N. Fraidenraich, and C. Tiba, "Photovoltaic pumping systems driven by tracking collectors. Experiments and simulation," Solar Energy, vol. 74, no. 1, pp. 45-52, 2003.

[5] H. K. Elminir, A. E. Ghitas, F. El-Hussainy, R. Hamid, M. M. Beheary, and K. M. Abdel-Moneim, "Optimum solar flatplate collector slope: case study for Helwan, Egypt," Energy Conversion and Management, vol. 47, no. 5, pp. 624-637, 2006.

[6] M. A. Ionită and C. Alexandru, "Dynamic optimization of the tracking system for a pseudo-azimuthal photovoltaic platform," Journal of Renewable and Sustainable Energy, vol. 4, Article ID 053117, 15 pages, 2012.
[7] S. Seme and G. Štumberger, "A novel prediction algorithm for solar angles using solar radiation and Differential Evolution for dual-axis sun tracking purposes," Solar Energy, vol. 85, no. 11, pp. 2757-2770, 2011.

[8] E. Calabrò, "The disagreement between anisotropic-isotropic diffuse solar radiation models as a function of solar declination: computing the optimum tilt angle of solar panels in the area of southern-Italy," Smart Grid and Renewable Energy, vol. 3, no. 4, pp. 253-259, 2012.

[9] B. Y. H. Liu and R. C. Jordan, "The interrelationship and characteristic distribution of direct, diffuse and total solar radiation," Solar Energy, vol. 4, no. 3, pp. 1-19, 1960.

[10] D. G. Erbs, S. A. Klein, and J. A. Duffie, "Estimation of the diffuse radiation fraction for hourly, daily and monthly-average global radiation," Solar Energy, vol. 28, no. 4, pp. 293-302, 1982.

[11] M. Iqbal, "Prediction of hourly diffuse solar radiation from measured hourly global radiation on a horizontal surface," Solar Energy, vol. 24, no. 5, pp. 491-503, 1980.

[12] A. Skartveit and J. A. Olseth, "A model for the diffuse fraction of hourly global radiation," Solar Energy, vol. 38, no. 4, pp. 271-274, 1987.

[13] J. D. Garrison, "A study of the division of global irradiance into direct and diffuse irradiance at thirty-three U.S. sites," Solar Energy, vol. 35, no. 4, pp. 341-351, 1985.

[14] D. T. Reindl, W. A. Beckman, and J. A. Duffie, "Diffuse fraction correlations," Solar Energy, vol. 45, no. 1, pp. 1-7, 1990.

[15] E. L. Maxwell, "A quasi-physical model for converting hourly global horizontal to direct normal insolation," Tech. Rep. SERI/TR-215-3087, Solar Energy Institute, Golden, Colo, USA, 1987.

[16] R. R. Perez, P. Ineichen, E. L. Maxwell, R. D. Seals, and A. Zelenka, "Dynamic global-to-direct irradiance conversion models," in Proceedings of ISES Solar World Congress, pp. 951956, Denver, Colo, USA, 1992.

[17] G. Qiu and S. B. Riffat, "Optimum tilt angle of solar collectors and its impact on performance," International Journal of Ambient Energy, vol. 24, no. 1, pp. 13-20, 2003.

[18] J. I. Yellott, "Utilization of sun and sky radiation for heating cooling of buildings," ASHRAE Journal, vol. 15, no. 12, pp. 31$42,1973$.

[19] G. Lewis, "Optimum tilt of a solar collector," Solar and Wind Technology, vol. 4, no. 3, pp. 407-410, 1987.

[20] H. P. Garg, Advances in Solar Energy Technology, Reidel, Boston, Mass, USA, 1987.

[21] P. J. Lunde, Solar Thermal Engineering, John Wiley \& Sons, New York, NY, USA, 1980.

[22] A. Angstrom, "Solar and terrestrial radiation," Quarterly Journal of the Royal Meteorological Society, vol. 50, pp. 121-126, 1924.

[23] G. N. Tiwari and S. Suneja, Solar Thermal Engineering System, Narosa Publishing, New Dehli, India, 1997.

[24] I. Ulfat, F. Ahmad, and I. Siddiqui, "Determination of Angstrom coefficient for the prediction of monthly average daily Gobal Solar Radiation Horizontal surface at Karachi, Pakistan," Karachi University Journal of Science, vol. 33, pp. 7-11, 2005.

[25] G. Stanhill and S. Moreshet, "Global radiation climate changes: the world network," Climatic Change, vol. 21, no. 1, pp. 57-75, 1992.

[26] B. G. Liepert and G. J. Kukla, "Decline in global solar radiation with increased horizontal visibility in Germany between 1964 and 1990," Journal of Climate, vol. 10, no. 9, pp. 2391-2401, 1997. 
[27] S. A. Klein, "Calculation of monthly average insolation on tilted surfaces," Solar Energy, vol. 19, no. 4, pp. 325-329, 1977.

[28] R. Perez, P. Ineichen, R. Seals, J. Michalsky, and R. Stewart, "Modeling daylight availability and irradiance components from direct and global irradiance," Solar Energy, vol. 44, no. 5, pp. 271-289, 1990.

[29] L. Robledo and A. Soler, "Modelling irradiance on inclined planes with an anisotropic model," Energy, vol. 23, no. 3, pp. 193201, 1998.

[30] F. J. Olmo, J. Vida, I. Foyo, Y. Castro-Diez, and L. AladosArboledas, "Prediction of global irradiance on inclined surfaces from horizontal global irradiance," Energy, vol. 24, no. 8, pp. 689-704, 1999.

[31] L. Wenxian, G. Wenfeng, P. Shaoxuan, and L. Enrong, "Ratios of global radiation on a tilted to horizontal surface for Yunnan Province, China," Energy, vol. 20, no. 8, pp. 723-728, 1995.

[32] D. H. W. Li and T. N. T. Lam, "Determining the optimum tilt angle and orientation for solar energy collection based on measured solar radiance data," International Journal of Photoenergy, vol. 2007, Article ID 85402, 2007.

[33] H. D. Kambezidis, B. E. Psiloglou, and C. Gueymard, "Measurements and models for total solar irradiance on inclined surface in Athens, Greece," Solar Energy, vol. 53, no. 2, pp. 177-185, 1994.

[34] T. Muneer, Solar Radiation and Daylight Models, Elsevier, Berlin, Germany, 2nd edition, 2004.

[35] T. Muneer and M. M. Hawas, "Correlation between daily diffuse and global radiation for India," Energy Conversion and Management, vol. 24, no. 2, pp. 151-154, 1984.

[36] J. K. Page, The Estimation of Monthly Mean Value of Daily Short Wave Irradiation on Vertical and Inclined Surfaces from Sunshine Records for Latitudes $60^{\circ} \mathrm{N}$ to $40^{\circ} \mathrm{S}$. BS32, Department of Building Science, University of Sheffield, Sheffield, UK, 1977.

[37] J. A. Duffie and W. A. Beckman, Solar Engineering of Thermal Process, John Wiley \& Sons, New York, NY, USA, 1991.

[38] J. LeQuere, "Rapport sur la comparaison des methods de calcul des besoins de chauffage des logements," Tech. Rep. CSTB TEAS 87, CSTB, Paris, France, 1980.

[39] J. E. Hay and J. A. Davies, "Calculation of the solar radiation incident on an inclined surface," in Proceedings of the 1st Canadian Solar Radiation Data Workshop, J. E. Hay and T. K. Won, Eds., pp. 59-72, Toronto, Canada, 1980.

[40] T. M. Klucher, "Evaluation of models to predict insolation on tilted surfaces," Solar Energy, vol. 23, no. 2, pp. 111-114, 1979.

[41] R. R. Perez, J. T. Scott, and R. Stewart, "An anisotropic model for diffuse radiation incident on slopes of different orientations and possible applications to CPCs," in Proceedings of American Solar Energy Society (ASES '83), pp. 883-888, Minneapolis, Minn, USA, 1983.

[42] R. Perez, R. Seals, P. Ineichen, R. Stewart, and D. Menicucci, "A new simplified version of the perez diffuse irradiance model for tilted surfaces," Solar Energy, vol. 39, no. 3, pp. 221-231, 1987.

[43] T. Muneer, Solar Radiation and Daylight Models for the Energy Efficient Design of Buildings, Architectural Press, Oxford, UK, 1997.

[44] E. Calabrò, "Determining optimum tilt angles of photovoltaic panels at typical north-tropical latitudes," Journal of Renewable and Sustainable Energy, vol. 1, no. 3, Article ID 033104, 6 pages, 2009.

[45] S. Naihong, N. Kameda, Y. Kishida, and H. Sonoda, "Experimental and Theoretical study on the optimal tilt of photovoltaic panels," Journal of Asian Architecture and Building Engineering, vol. 5, pp. 399-405, 2006. 


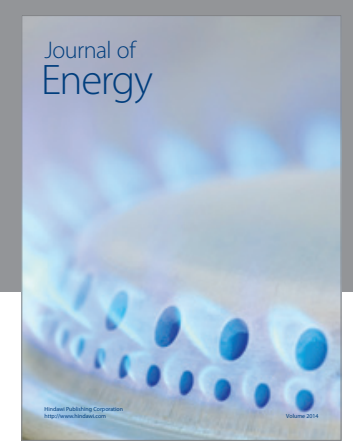

Journal of

Industrial Engineering
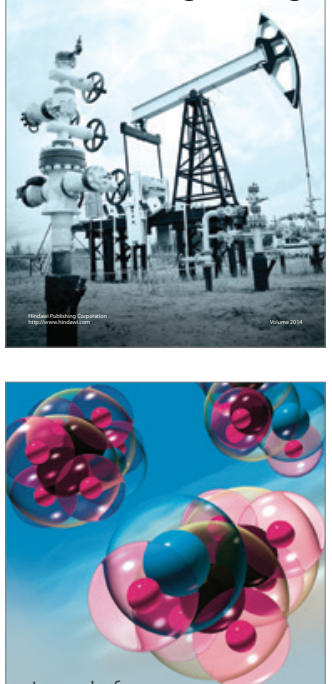

Fuels
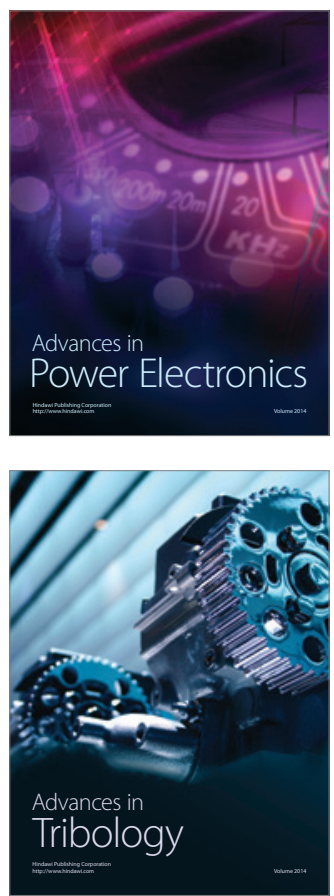

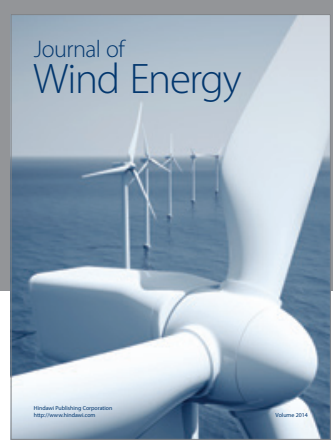

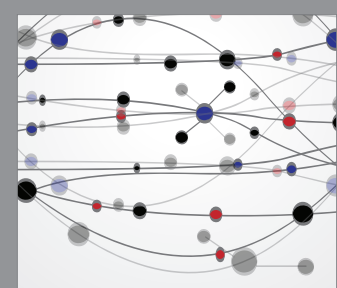

The Scientific World Journal

Submit your manuscripts at http://www.hindawi.com

Journal of

Structures
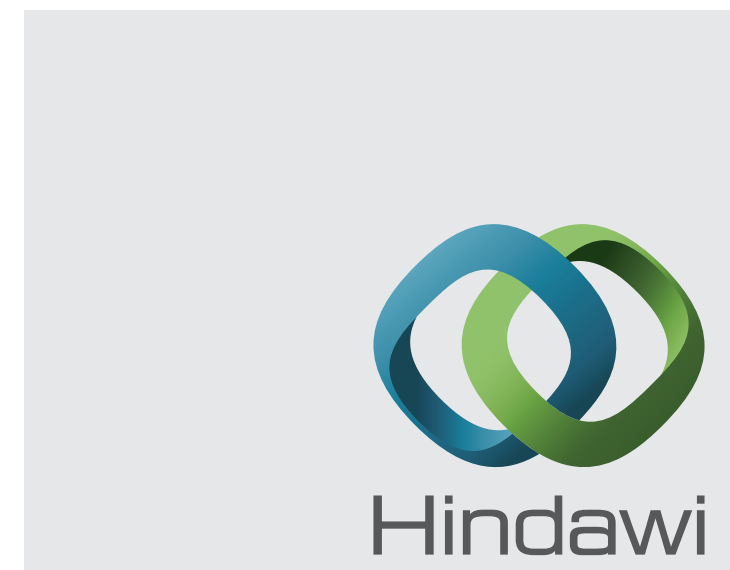

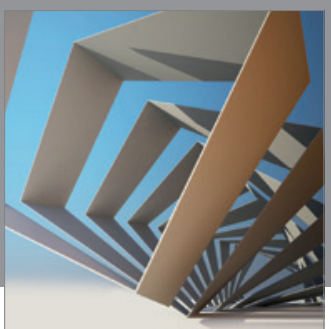

Rotating

Machinery
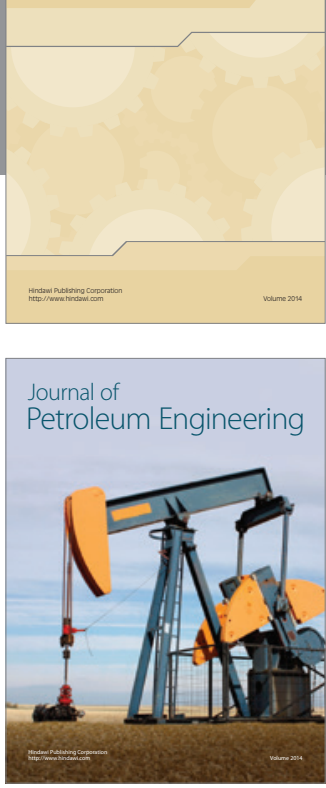

Journal of

Solar Energy
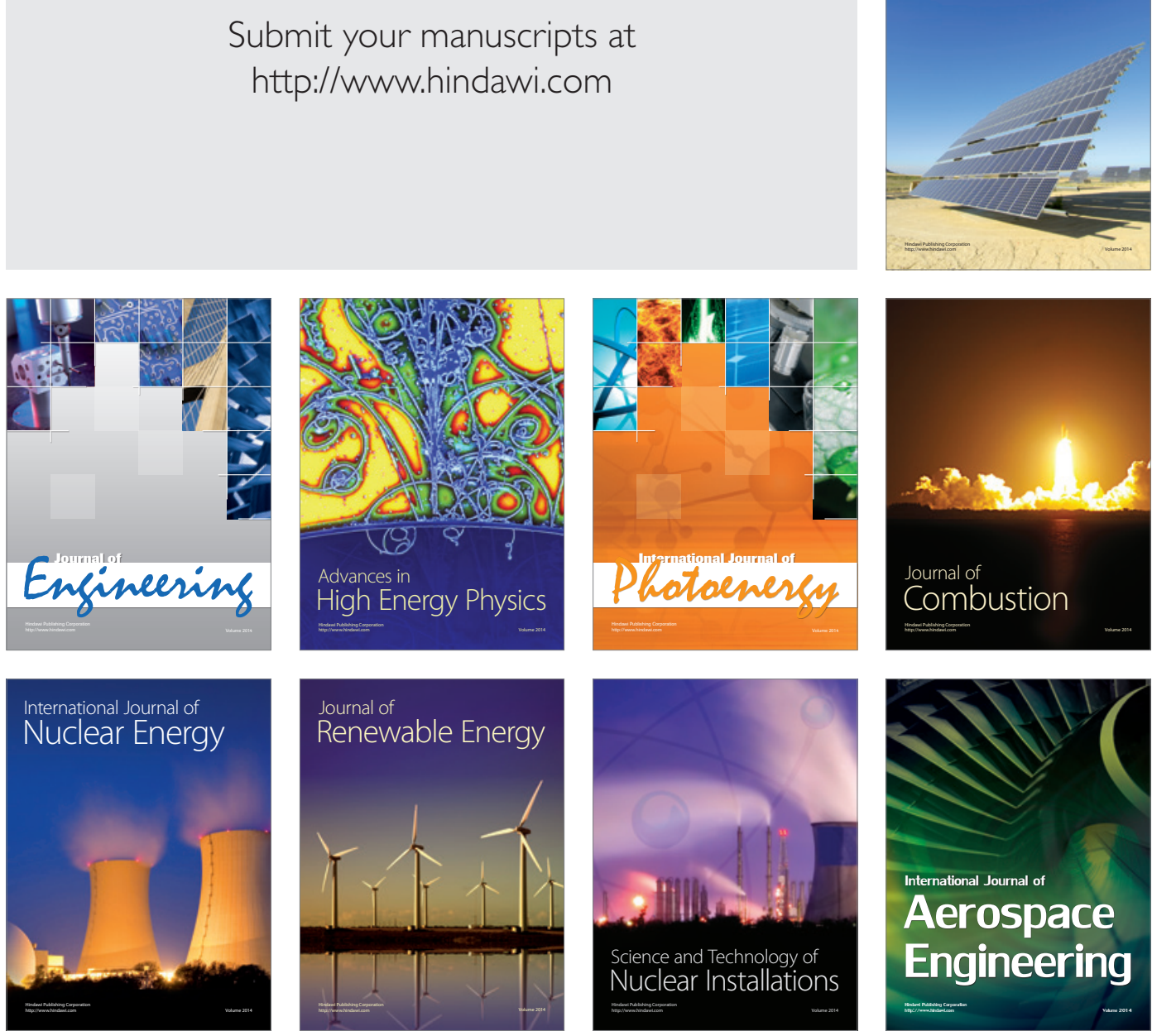